\title{
OPPORTUNISTIC PROTOZOAN INFECTIONS OF CARNIVORES
}

\author{
Mravcová, K., Ferko, M., Štrkolcová, G., Goldová, M. \\ Institute of Parasitology \\ University of Veterinary Medicine and Pharmacy, Komenského 73, 04181 Košice \\ Slovakia \\ maria.goldova@uvlf.sk
}

\section{ABSTRACT}

Giardiasis and cryptosporidiosis are protozoan infections of the digestive tract and one of the most frequent causes of enteritis in dogs and cats, associated with acute and chronic diarrhoea. Generally, the risk of infection is higher for younger individuals in which the overall clinical picture and the course of disease are more serious. In this study we investigated the prevalence of giardiasis and cryptosporidiosis in dogs in Košice district of eastern Slovakia. From September 2015 until November 2016, we examined samples of faeces from 100 dogs from two shelters. Giardia duodenalis was diagnosed by the flotation method according to Faust, and by the molecular biologic method (Nested PCR). For the diagnosis of cryptosporidium oocysts, we used a staining method according to Kinyoun, and for detection of the presence of Cryptosporidium spp. a sandwich ELISA method. The total prevalence of these protozoan infections were $22 \%$ $(22 / 100)$, and of that, $19 \%$ of the samples $(19 / 100)$ were positive for Giardia duodenalis and $3 \%(3 / 100)$ for the Cryptosporidium spp. In the shelter in Haniska, the giardia cysts were present in 9/54 samples (16.6\%) and cryp- tosporidia oocysts in 1/54 (1.85\%) samples of the faeces. In the Malá Farma shelter, 10/46 (21.73\%) samples were positive for $G$. duodenalis and 2/46 (4.34\%) showed positivity for Cryptosporidium spp.

Key words: cryptosporidiosis; dog shelters; giardiasis

\section{INTRODUCTION}

In September 2004, the World Health Organization (WHO) included cryptosporidiosis and giardiasis in the "Neglected Diseases Initiative" [19]. These protozoan infections belong among opportunistic waterborne and foodborne diseases [23]. They can cause serious infections with pronounced clinical signs, particularly in immunosuppressed individuals [13].

Giardiasis is a protozoan parasitic disease affecting the gastrointestinal tract. Giardia duodenalis is located in the distal duodenum and proximal and central jejunum, blocking the absorption of nutrients. It is one of the most wide spread intestinal infections in both the temperate and tropical zones. Giardiasis can present with a broad range of clini- 
cal manifestation from asymptomatic through moderate up to serious, and the outcome may also be fatal. The clinical signs usually include diarrhoea frequently alternating with constipation, abdominal pain, excess fat in the faeces (steatorrhea) and flatulence [14]. Young and immunodeficient individuals are afflicted most frequently. In addition to its classical intestinal presentation, giardiasis may cause ocular complications, arthritis, skin allergies or myopathy. Moreover, giardiasis is now a well-established cause of failure to thrive, stunting and growth retardation in human and other animals, diminished cognitive functions, and chronic fatigue. Finally, Giardia may lead to post-infectious functional gastrointestinal disorders such as irritable bowel syndrome and functional dyspepsia. A few cases of Giardia trophozoites associated with tumoral masses have also been reported, but a definite cause and effect relationship between giardiasis and cancer have yet to be established [12].

Giardia duodenalis is divided into eight genetically distinct genotypes (assemblages) A- $\mathrm{H}$; the $\mathrm{A}$ and $\mathrm{B}$ assemblages exhibit the greatest zoonotic potential. Assemblages $\mathrm{C}$ and $\mathrm{D}$ were detected in dogs and other canines [3].

Cryptosporidia are single celled parasites included in the phyllum Apicomplexa. They are cosm opolite parasites with an affinity for the digestive tract, but affecting also the respiratory tract. Clinical manifestations are common in the young, while in older animals the infections may be asymptomatic. The disease in carnivores is caused by oocysts of Cryptosporidium canis, C. felis, C. parvum, C. muris and C. meleagridis [16]. In humans the disease is caused mainly by Cryptosporidium hominis, particularly in immunodeficient patients and may raise serious risk with fatal consequences to HIV-positive individuals. Children infected with $C$. hominis shed higher levels of oocysts because they have an underdeveloped immune system and oocysts can proliferate easier, possibly contributing to the increased prevalence and spread of C. hominis within these communities [22]. Because humans are infected mostly with Cryptosporidium hominis and C. parvum, the role of companion animals in the transmission of human cryptosporidiosis may be limited. Even though a small number of humans are infected with C. canis and C. felis, recent findings of concurrent C. hominis infection in C. canis-infected persons suggest that many of the C. canis infections in humans may be due to anthroponotic rather than zoonotic transmission [4].

Giardiasis and cryptosporidiosis are transmitted directly by the faecal-oral route and by the consumption of food or water contaminated with cysts and oocysts [7]. The transmission of both diseases can occur from man to man, from animal to animal, and by zoonotic transmission (from animal to man and vice versa). Another potential way of transmission is indirect, through a contaminated environment [17]. Waterborne contamination is a growing concern causing widespread disease outbreaks. Factors that have contributed to the emergence of cryptosporidiosis in animals include increased environmental contamination and trends in livestock production [18].

The aim of this study was to determine the prevalence of giardiasis and cryptosporidiosis in dog shelters located in the Košice district of eastern Slovakia, and to suggest potential ways to decrease these opportunistic infections.

\section{MATERIALS AND METHODS}

From September 2015 until November 2016, we examined the faeces of dogs from two shelters: Union for mutual help between humans and animals (UVP) in Haniska village (54 samples) about $34 \mathrm{~km}$ away from Košice and Malá Farma (private shelter) at the periphery of Košice (46 samples) in eastern Slovakia.

The faeces were collected from dogs of different age categories and breeds including mongrels. The faecal samples were examined by flotation method according to Faust et al. [6] using zinc sulphate solution (specific gravity $1.18 \mathrm{~g} . \mathrm{cm}^{-3}$ ), with microscopic observation of Giardia cysts [8]. The molecular diagnosis of Giardia duodenalis was performed by the nested PCR as described by Sula i m a n et al. [20], based on the amplification of the triosephosphate isomerase (tpi) gene. Cryptosporidium oocysts were diagnosed using the staining method of Kinyoun [8]. The presence of Cryptosporidium spp. was confirmed by the commercial kit sandwich ELISA (Diagnostic automation, Inc., CA, USA, 91302).

\section{RESULTS}

In the UVP shelter, the dogs lived in rather crowded sheds and the hygiene level in this shelter was low. Also, veterinary care of the animals was limited. The total prevalence of Giardia duodenalis in this shelter reached $16.6 \%$ (9/54). In faecal smears stained with the Kinyoun stain, 
we detected Cryptosporidium spp. in 1 out of 54 examined $\operatorname{dog}(1.85 \%)$. This sample was positive also by the ELISA method.

In the private shelter in Malá Farma, G. duodenalis cysts were present in $21.73 \%$ of the samples (10/46). The examination of faecal smears stained according to Kinyoun, showed the presence of Cryptosporidium spp. oocysts in $2.17 \%(1 / 46)$ of the samples and the ELISA test confirmed the presence of Cryptosporidium antigen in $4.34 \%$ of the samples (2/46).

Eight of the microscopically positive samples were subjected to genotyping of $G$. duodenalis by the nested PCR. After BLAST analysis and subsequent comparison of the sequences of our positive samples with sequences existing in GenBank, we detected $99 \%$ to $100 \%$ similarity with assemblage $\mathrm{C}$ in four samples which corresponded to access number JN587492, obtained from dog from Croatia, and AY228641, obtained from a dog from the USA.

\section{DISCUSSION}

The examination of dogs kept under poor hygiene conditions in dog shelters in Košice district showed a high prevalence of giardiasis. Of the total of 100 samples, cysts of G. duodenalis were found in 19 samples (19\%). In the stained faecal smears we found Cryptosporidium spp. only in $2 \%$ of the samples (2/100) and cryptosporidium antigen was detected in 3 samples. The sensitivity of the detection of Cryptosporidium spp. by ELISA test is higher.

In 2011, the prevalence of giardiasis in the dog shelters in Košice reached $69.1 \%$ in younger dogs and $39.9 \%$ in older ones [10]. This prevalence was higher in comparison with that determined in the study by Adamová et al. [1], conducted in 2014, which showed that the prevalence of $G$. duodenalis reached $33 \%$. In the study conducted in Poland by Bajer et al. [2], the authors detected $31.9 \%$ prevalence of giardiasis. The prevalence of this parasitosis detected in Czechia was much lower in comparison with Poland and reached only $2.2 \%$ [5]. The zoonotic potential of Giardia duodenalis is related mainly to assemblages A and $\mathrm{B}$, but the latest research indicated that the zoonotic risk is associated also with other assemblages. By means of molecular biologic methods, Štrkolcová et al. [21] confirmed for the first time in Europe, the occurrence of canine assemblage C of Giardia duodenalis in a patient in
Košice, which indicated the potential role of dogs in zoonotic transmission of this pathogen. In this study, the molecular PCR method confirmed the presence of assemblage $\mathrm{C}$ in 4 samples.

In 2011, 125 dogs were examined in Košice for the presence of Cryptosporidium spp. and the prevalence reached $7.2 \%$ in younger dogs and $1.4 \%$ in older ones [10]. Adamová et al. [1] observed that the prevalence of Cryptosporidium spp. reached $9.09 \%$ in the Košice district. The examination of samples of dog faeces in Spain showed the presence of Cryptosporidium spp. in $4.1 \%$ of the cases (8/194) [9]. In Poland, oocysts of Cryptosporidium spp. were found in $1.2-12.5 \%$ of the dogs $[2,15]$ but detection of the copro-antigen indicated a higher prevalence of this protozoan than that obtained by microscopical examinations [11].

Insufficient hygiene and welfare, stress and other factors may contribute to worsen the health of some animals. The dog shelters were inadequate with regard to their capacity and hygiene level. All of the above factors support transmission of these opportunistic protozooans with zoonotic potential. It is essential to prevent contact of sick individuals with humans and other animals. The presence of individuals infected with zoonotic species/assemblages/ genotypes of cryptosporidia and giardia possess a threat to public health.

\section{CONCLUSIONS}

Dogs, cats and domestic ruminants are typical hosts of cryptosporidia and giardia. These animals are in close contact with humans and thus present considerable risk of spreading these infections, particularly of the species with zoonotic potential. The examination of dogs in the two shelters confirmed that these infections are still present in the Košice region. Effective therapy is unknown up to the present. To decrease the prevalence of these protozoans one should start with measures that can improve the immunity of dogs and other animal species. It is also important to improve the conditions to which the animals are exposed, improve their hygiene and nutrition, and ensure regular sanitation of the premises. Other very important preventive measures include provision of adequate veterinary care and regular monitoring of the prevalence of these opportunistic infections. 


\section{ACKNOWLEDGEMENTS}

The study was supported by the grant of the State Agency VEGA No. 1/0455/15; Internal Grant Agency IGA UVLF 01/2016; Medical University Park in Košice (MediPark, Košice) ITMS:26220220185 supported by Operational Programme Research and Development (OP VaV-2012/2.2/08RO) (Contract No. OPVaV/12/2013).

\section{REFERENCES}

1. Adamová, V., Štrkolcová, G., Goldová, M., 2014: Giardiasis and cryptosporidiosis in dogs in Košice. Folia Veterinaria, 58, $2,69-71$

2. Bajer, A., Bednarska, M., Rodo, A., 2011: Risk factors and control of intestinal parasite infections in sled dogs in Poland. Vet. Parasitol., 175, 343-350.

3. Cacció, S.M., Ryan, U., 2008: Molecular epidemiology of giardiasis. Mol. Biochem. Parasitol., 160, 75-80.

4. Cama, V., Gilman, R.H., Vivar, A., Ticona, E., Ortega, Y., Bern, C., Xiao, L., 2006: Mixed Cryptosporidium infections and HIV. Emerg. Infect. Dis., 12, 1025-1028.

5. Dubná, S., Langrová, I., Nápravník, J., Jankovská, I., Vadlejch, J., Pekár, S., Frchtner, J., 2007: The prevalence of intestinal parasites in dogs from Prague, rural areas, and shelters of the Czech Republic. Vet. Parasitol., 145, 120-128.

6. Faust, E. C., D’Antonio, J.S., Odom, V., Miller, M. J., Peres, C., Sawitz, W. et al., 1938: A critical study of clinical laboratory techniques for the diagnosis of protozoan cysts and helminth eggs in faeces. Am. J. Trop. Med. Hyg., 18, 169-183.

7. Feng, Y., Xiao, L., 2011: Zoonotic potential and molecular epidemiology of Giardia species and Giardiasis. Clin. Microbiol. Rev., 24, 110-140.

8. Garcia, L. S., Bruckner, D. A., 1977: Collection, preservation, and shipment of faecal specimens. Garcia, L. S., Bruckner, D. A. (Eds.): Diagnostic Medical Parasitology, 3rd edn., ASM Press, Washington D. C., 593-607.

9. Gil, H., 2017: Detection and molecular diversity of Giardia duodenalis and Cryptosporidium spp. in sheltered dogs and cats in northern Spain. Infect. Genet. Evol., 50, 66-68.

10. Goldová, M., Valenčáková, A., Mojžišová, J., Halánová, M., Letková, V., Ravaszová, P., 2011: Occurrence of Giardia and Cryptosporidium in dogs. In Proceedings of SEVC - 46th Southern European Veterinary Conference, Sept.29-Oct.2, Barcelona.
11. Gundłach, J. L., Sadzikowski, A. B., Studzińska, M. B., Tomczuk, K., 2004: Invasion of Giardia spp. and Cryptosporidium spp. in dogs and cats. Medycyna Weterynaryjna, 60, 12021203.

12. Halliez, M.C.M., Buret, A.G., 2013: Extra-intestinal and long-term consequences of Giardia duodenalis infections. World J. Gastroenterol., 19, 8974-8985.

13. Hunter, P. R., Hadfield, S. J., Wilkinson, D., Lake, I. R., Harrison, F.C.D. et al., 2007: Subtypes of Cryptosporidium parvum in humans and disease risk. Emerg. Infect. Dis., 13, 82-88.

14. Jíra, J., 2009: Medical Protozoology. Protozoan Diseases (In Czech). Galén, 567 pp.

15. Majewska, A.C., Werner, A., Słodkowicz, A., Dąbrowski, P., Luty, T., 2001: Prevalence of intestinal protozoan parasites in dogs and cats in the Poznań area. Annals of Parasitology, 47, 30.

16. Nichols, G.L., Chalmers, R.M., Hadfield, S. J., 2014: Molecular epidemiology of human cryptosporidiosis. Cryptosporidium: Parasite and Disease. Springer, 81-147.

17. Plutzer, J., Ongerth, J., Karanis, P., 2010: Giardia taxonomy, phylogeny and epidemiology: Facts and open questions. International Journal of Hygiene and Environmental Health, 213, $321-333$.

18. Putigniani, L., Menichella, D., 2010: Global distribution, public health and clinical impact of the protozoan pathogen Cryptosporidium. Interdiscip. Perspect. Infect. Dis., Epub, https://www.ncbi.nim.nih.gov.pubmed/207006669.

19. Savioli, L., Smith, H., Thompson, R.C.A., 2006: Giardia and Cryptosporidium join the "Neglected Diseases Initiative". Trends Parasitol., 22, 203-208.

20. Sulaiman, I. M., Fayer, R., Bern, C., Gilman, R.H., Trout, J. M., Schantz, P. M. et al., 2003: Triosephosphate isomerase gene characterization and potential zoonotic transmission of Giardia duodenalis. Emerg. Infect. Diseases, 9, 1444-1452.

21. Štrkolcová, G., Madar, M., Hinney, B., Goldová, M., Mojžišová, J., Halánová, M., 2015: Dog’s genotype of Giardia duodenalis in human: first evidence in Europe. Acta Parasitologica, 60, 796-799.

22. Xiao, L., Bern, C., Limor, J., Sulaiman, I., Roberts, J., Checkley, W. et al., 2001: Identification of 5 types of Cryptosporidium parasites in children in Lima, Peru. J. Infect. Dis., $183,492-497$.

23. Xiao, L., 2010: Molecular epidemiology of cryptosporidiosis: an update. Exp. Parasitol., 124, 80-89.

Received July10, 2017

Accepted October 2, 2017 